Revista Brasileira de Agricultura Irrigada v.11, nº.7, p. 2052 - 2062, 2017

ISSN 1982-7679 (On-line)

Fortaleza, CE, INOVAGRI - http://www.inovagri.org.br

DOI: $10.7127 /$ rbai.v11n700682

Protocolo 682.17 - 15/05/2017 Aprovado em 23/08/2017

\title{
TOLERÂNCIA À SALINIDADE E QUALIDADE DE MUDAS DE NONI SOB DIFERENTES AMBIENTES E MATÉRIA ORGÂNICA
}

\author{
Maria Cristina Martins Ribeiro de Souza ${ }^{1}$, Ademir Silva Menezes ${ }^{2}$, Rafael Santiago da \\ Costa $^{3}$, Aiala Vieira Amorim ${ }^{4}$, Claudivan Feitosa de Lacerda ${ }^{5}$, Maria da Saúde de Sousa \\ Ribeiro $^{6}$
}

\section{RESUMO}

Objetivou-se com este trabalho avaliar os efeitos da salinidade da água de irrigação sobre o crescimento inicial das plantas de noni, cultivadas em dois ambientes, na ausência ou presença de matéria orgânica. O delineamento experimental foi em blocos ao acaso disposto no esquema de parcelas subsubdivididas, com 5 repetições. As parcelas foram constituídas pelos ambientes de cultivo (céu aberto e telado), as subparcelas pelos níveis de salinidade da água de irrigação (CEa: 0,3;1,5; 3,0; 4,5 e 6,0 dS m m $^{-1}$ ) e as subsubparcelas representadas pela ausência e presença de matéria orgânica. Foram feitas avaliações de condutividade elétrica do extrato de saturação (CEes) aos 110 dias após a aplicação dos tratamentos (DAT). Avaliou-se o crescimento das plantas aos, 30, 60, 90 e 110 DAT e a qualidade das plantas aos 110 DAT. A salinidade da água de irrigação provocou incremento linear na CEes, independente do ambiente de cultivo, sendo os valores sempre maiores na presença do insumo orgânico. As plantas de noni cultivadas sob condições de telado se mostraram mais tolerantes à salinidade do que as cultivadas à céu aberto. O ambiente à céu aberto proporcionou melhor qualidade de mudas, porém a matéria orgânica não atenuou os efeitos da salinidade sobre o crescimento inicial e da qualidade de mudas de noni nos ambientes avaliados.

Palavras-chave: crescimento, estresse salino, Morinda citrifolia, sombreamento.

\footnotetext{
${ }^{1}$ Professora Doutora, Instituto Federal do Ceará (IFCE) - Campus de Sobral, Av. Dr. Guarani, 317 - Derby Clube, CEP: 62040-730, Sobral - CE, Brasil, profmariacristinasouza@gmail.com

${ }^{2}$ Mestre em Ciência do Solo, Universidade Federal do Ceará (UFC), Av. da Universidade, 2853 - Benfica, CEP: 60020-180, Fortaleza - CE, Brasil, amenezzes@gmail.com

${ }^{3}$ Graduando em Agronomia, Instituto de Desenvolvimento Rural (IDR), Universidade da Integração Internacional da Lusofonia Afro-Brasileira (UNILAB), Av. da Abolição, 3 - Centro, CEP: 62790-000, Redenção - CE, Brasil, rafaelsantiagodacosta@yahoo.com.br

${ }^{4}$ Professora Doutora, Instituto de Desenvolvimento Rural (IDR), UNILAB, Av. da Abolição, 3 - Centro, CEP: 62790-000, Redenção - CE, Brasil, aialaamorim@unilab.edu.br

${ }^{5}$ Professor Doutor, UFC, Av. da Universidade, 2853 - Benfica, CEP: 60020-180, Fortaleza - CE, Brasil, claudivan_@hotmail.com

${ }^{6}$ Doutoranda em Engenharia Agrícola, Universidade Federal do Ceará (UFC), Av. da Universidade, 2853 -

Benfica, CEP: 60020-180, Fortaleza - CE, Brasil, sauderibeiro@hotmail.com
} 


\title{
TOLERANCE TO SALINITY AND QUALITY OF NONI SEEDLINGS UNDER DIFFERENT ENVIRONMENTS AND ORGANIC MATTER
}

\begin{abstract}
The objective of this work was to evaluate the effects of salinity of irrigation water on the initial growth of the plants of noni, cultivated in two environments, in the absence or presence of organic matter. The statistical design was adopted in random blocks in a split plot scheme, with 5 repetitions. The plots were set up by cultivation environments (open sky and screenhouse), the subplots by salinity levels of irrigation water (CEw: 0.3; 1.5; 3.0; 4.5 and $6.0 \mathrm{dS} \mathrm{m}^{-1}$ ) and the subsubplots represented by the absence and presence of organic matter. The electrical conductivity of the saturation extract (CEes) was measured at 110 days after application of the treatments (DAT). The plant growth parameters were evaluated at 30, 60, 90 and 110 DAT. The salinity of irrigation water caused linear increment in CEes, independent of the cultivation environment, being the values always bigger in presence of organic matter. Noni plants grown under screen conditions were more tolerant to salinity than those grown in the open. The open air environment provided better quality of seedlings, but the organic matter did not attenuate the effects of salinity on initial growth and quality of noni seedlings in the evaluated environments.
\end{abstract}

Keywords: growth, salt stress, Morinda citrifolia, seasonality.

\section{INTRODUÇÃO}

O noni (Morinda citrifolia L.) é uma planta pertencente à família Rubiaceae, sendo utilizada como medicinal, principalmente pelos povos polinésios, para diversas enfermidades como: alergia, artrite e asma (YANG et al., 2010) A fruta embora bastante consumida na Ásia há mais de 2000 anos é praticamente desconhecida no Brasil. Sua introdução ocorreu há poucos anos e, ainda não há material propagativo suficiente para 0 cultivo em escala comercial (BASAR et al., 2010). No que diz respeito ao cultivo desse vegetal em ambiente salino, Singh (2012) afirma ser, o noni, uma cultura tolerante aos efeitos salinos e alcalinos dos solos, podendo se desenvolver tanto em regiões de clima seco como de clima úmido.

A salinidade é um dos estresses abióticos que mais limita o crescimento, desenvolvimento e a produtividade das plantas em todo o mundo (FREIRE et al., 2011), sendo um dos principais problemas enfrentados na produção de culturas. As áreas salinas no mundo se concentram principalmente em regiões áridas e semiáridas e são decorrentes de vários fatores, tais como baixa precipitação pluviométrica, alta evaporação, material de origem dos solos, irrigação mal conduzida, qualidade da água e drenagem inadequada (DANTAS et al., 2006).

Vários são os efeitos provocados pelo estresse salino na planta: o efeito osmótico, o tóxico por elementos minerais (cloretos, boro, sódio) e os indiretos, que acontecem quando as altas concentrações de cloreto, sódio ou outros cátions na solução interferem nas condições físicas do solo ou na disponibilidade de outros elementos (QUEIROZ et al., 2009). Em condições salinas as plantas não crescem, ou crescem em taxas menores, podendo esse fato ser atribuído ao gasto adicional de energia que a planta necessita para os diversos mecanismos que garantem sua sobrevivência em meios salinos (FERNANDES et al., 2008).

Além da salinidade, outros fatores devem ser considerados quando se avalia o crescimento, desenvolvimento e tolerância à salinidades dos vegetais, dentre eles destaca-se as condições climáticas e a composição de matéria orgânica do solo. Pedrotti (2015) afirma que os diferentes graus de luminosidade causam, em geral, mudanças morfológicas na planta, sendo que os efeitos das diferenças de intensidade de luz são significativos para o 
crescimento das plantas, principalmente no que se refere ao acúmulo de matéria seca, em condições naturais.

No que se refere à composição de matéria orgânica do solo Cavalcante et al. (2007), afirmaram que a utilização de insumos orgânicos podem estimular a liberação de substâncias húmicas causando superioridade no crescimento vegetativo. A proliferação de microorganismos contida no material orgânico adicionados aos solos pode aumentar o grau de disponibilidade de nutrientes às plantas, o que favorece o desenvolvimento das mesmas (RAJENDRAN; DEVARJ, 2004). Em adição, Souto et al. (2013) observaram que ao utilizar biofertilizante bovino nas plantas de noni irrigadas com água de diferentes níveis de salinidades, ocorreu um ganho médio na altura de $24,35 \%$, em relação aos tratamentos sem esterco bovino líquido.

Partindo do pressuposto acima, fica evidente que pesquisas de espécies e cultivares mais tolerantes, capazes de atingir rendimentos economicamente viáveis e em condições de salinidade elevada, possibilitam a ocupação de áreas salinizadas que são constantemente abandonadas ou o uso de águas salobras na irrigação. Portanto, objetivou-se com o presente experimento, avaliar o crescimento inicial e a qualidade de mudas do noni, cultivado sob irrigação com águas salinas em solos sem e com adição de matéria orgânica, em ambiente a céu aberto e telado.

\section{MATERIAL E MÉTODOS}

O experimento teve duração total de cerca de sete meses, desde o preparo das mudas de noni, em maio de 2011, até a coleta em dezembro de 2011, e foi conduzido em dois ambientes, céu aberto e telado com malha preta e $50 \%$ de luminosidade, em um horto de produção de mudas da prefeitura municipal de Sobral - Ceará, localizadas pelas coordenadas geográficas de $3^{\circ} 41$ '10" de latitude Sul e 40²0'59" de longitude Oeste, com altitude média de $70 \mathrm{~m}$. Segundo a classificação de Köppen, a área do experimento está localizada numa região de clima do tipo Aw’, por possuir um clima tipicamente tropical, quente com chuvas de verão.

O delineamento estatístico adotado foi em blocos ao acaso disposto no esquema de parcelas subsubdivididas, com 5 repetições. As parcelas foram constituídas pelos ambientes de cultivo (céu aberto e telado), as subparcelas pelos níveis de salinidade da água de irrigação (CEa: 0,$3 ; 1,5 ; 3,0 ; 4,5$ e $6,0 \mathrm{dS} \mathrm{m}^{-1}$ ) e as subsubparcelas foram representadas pela ausência e presença de matéria orgânica. A combinação desses fatores resultou em 20 diferentes tratamentos, sendo que cada repetição foi constituída de três vasos (uma planta por vaso), totalizando 300 vasos.

As mudas de noni foram produzidas a partir de sementes obtidas em um plantio localizado no município de Trairi - CE. As sementes foram retiradas do fruto e foram lavadas em água corrente e colocadas para secar a sombra sobre papel absorvente durante 48 horas. As sementes foram semeadas em bandejas com 200 células e cheias com um substrato formulado de $50 \%$ de areia lavada + $50 \%$ de esterco de gado curtido. Aos 60 dias após a semeadura foram selecionadas as mudas mais vigorosas transplantadas para sacos pretos de polietileno nas dimensões de $15 \mathrm{~cm}$ de largura e $28 \mathrm{~cm}$ de comprimento, sanfonados e com furos, sendo acondicionada uma planta por saco.

O material utilizado no preenchimento dos sacos para o completo desenvolvimento das mudas foi uma mistura de esterco de gado (curtido) e solo, nas proporções de 1:1. Para cada 20 litros desta mistura, foram aplicados $500 \mathrm{~g}$ da formulação 4:14:8 (NPK). As mudas foram irrigadas diariamente com água de condutividade elétrica $0,3 \mathrm{dS} \mathrm{m}^{-1}$. Após a produção das mudas quando estas apresentavam 4 a 6 pares de folhas definitivas foram plantadas nos vasos com capacidade de 20 litros, para a condução do experimento.

Os vasos foram preenchidos com $50 \%$ de solo e a outra metade $25 \%$ de solo $+25 \%$ de composto orgânico, na parte inferior foi colocado $2 \mathrm{~cm}$ de brita para facilitar a drenagem. Os vasos foram identificados, colocados sobre tijolos para facilitar a coleta do material drenado e devidamente 
distribuídos de acordo com os tratamentos e ambientes testados. Foi realizado a análise das características químicas dos dois substratos e o resultado pode ser observado na Tabela 1.

Tabela 1. Características físicas e químicas dos substratos utilizados no experimento, Sobral - CE, 2011.

\begin{tabular}{|c|c|c|}
\hline Características & Tratamento sem Matéria Orgânica & Tratamento com Matéria Orgânica \\
\hline Classificação Textural & Areia & Areia \\
\hline \multicolumn{3}{|l|}{ Elemento } \\
\hline pH em água & 6,2 & 7,0 \\
\hline $\mathrm{CE}\left(\mathrm{dS} \mathrm{m}^{-1}\right)$ & 0,14 & 1,4 \\
\hline $\mathrm{P}\left(\mathrm{mg} \mathrm{dm}^{-3}\right)$ & 74,0 & 669,00 \\
\hline $\mathrm{Ca}^{+2}\left(\mathrm{mmol}_{\mathrm{c}} \mathrm{dm}^{-3}\right)$ & 42,0 & 40,0 \\
\hline $\mathrm{Mg}^{+2}\left(\mathrm{mmol}_{\mathrm{c}} \mathrm{dm}^{-3}\right)$ & 6,0 & 37,0 \\
\hline $\mathrm{Na}^{+}\left(\mathrm{mmol}_{\mathrm{c}} \mathrm{dm}^{-3}\right)$ & 1,2 & 16,17 \\
\hline $\mathrm{K}^{+}\left(\mathrm{mmol}_{\mathrm{C}} \mathrm{dm}^{-3}\right)$ & 1,47 & 24,07 \\
\hline $\mathrm{H}^{+}+\mathrm{Al}^{3+}\left(\mathrm{mmol}_{\mathrm{c}} \mathrm{dm}^{-3}\right)$ & 23,93 & 28,88 \\
\hline Matéria Orgânica $\left(\mathrm{g} \mathrm{kg}^{-1}\right)$ & 3,72 & 24,72 \\
\hline
\end{tabular}

Com o intuito de corrigir eventuais carências nutricionais do solo, foram aplicados, para cada vaso, em fundação $0,5 \mathrm{~g}$ de ureia, $1,0 \mathrm{~g}$ de superfosfato simples e $0,5 \mathrm{~g}$ de cloreto de potássio. Em cobertura foram aplicados $0,5 \mathrm{~g}$ de ureia e $0,5 \mathrm{~g}$ de cloreto de potássio, aos 30, 45 e 60 dias após a adubação de fundação. Por ocasião da $2^{\text {a }}$ cobertura, 45 dias após a adubação de fundação, foi aplicado 1 g planta $^{-1}$ de micronutriente (FTE Br-12). E aos 60 dias após a adubação de fundação foi feita adubação foliar com $2 \mathrm{mM}$ de sulfato de magnésio e $1 \mathrm{mM}$ de sulfato de cálcio somente nas plantas do tratamento controle.

Para atingir os níveis de condutividade elétrica da água de irrigação (CEa) desejados utilizaram-se diferentes quantidades de sais de $\mathrm{NaCl}, \quad \mathrm{CaCl}_{2} \cdot 2 \mathrm{H}_{2} \mathrm{O}$ e $\mathrm{MgCl}_{2} \cdot 6 \mathrm{H}_{2} \mathrm{O}$, na proporção de 7:2:1, obedecendo-se a relação entre CEa e a concentração $\left(\right.$ mmol $_{\mathrm{c}} \mathrm{L}^{-1}=\mathrm{CE} \mathrm{x}$ 10). As quantidades dos elementos químicos dos sais calculados eram preparados no laboratório de análise de solo e água para irrigação do Instituto Federal Ciência e Tecnologia (IFCE), Campus Sobral, e por ocasião da irrigação eram diluídos com água da testemunha $\left(0,3 \mathrm{dS} \mathrm{m}^{-1}\right)$ num balde com capacidade para 60 litros.

Após diluição procedia-se a leitura da condutividade elétrica das amostras das águas salinas com a finalidade de aferir os diferentes níveis desejados. Os tratamentos foram aplicados em dias alternados e a quantidade de solução aplicada às plantas foi de acordo com o princípio do lisímetro de drenagem. Mantendo-se o solo na capacidade de campo e adicionando-se uma fração de lixiviação de $20 \%$ para percolação. A aplicação da água foi feita de forma localizada, de modo a evitar o contato direto da mesma com as folhas.

Para avaliação do acúmulo de sais no solo, coletaram-se amostras de solos aos 110 dias após aplicação dos tratamentos. As amostras foram acondicionadas em bandejas de alumínio, identificadas e secas em estufa com circulação de ar forçado a $70{ }^{\circ} \mathrm{C}$. Depois de secas e destorroados foram determinados os valores da condutividade elétrica do extrato de saturação (CEes), no laboratório de análise de solo e água para irrigação do IFCE - Campus Sobral, seguindo os métodos analíticos descritos no Manual de Análises Químicas de Solos, Plantas e Fertilizantes (SILVA, 2009).

Foram avaliados os dados de crescimento, e a partir deles, calcularam-se as perdas percentuais em relação ao menor nível de salinidade (redução em \%), as quais foram utilizadas como índices para comparar a tolerância do noni à salinidade nos dois ambientes de cultivo (Tabela 2), conforme Fageria et al. (2010). 
Tabela 2. Classificação de espécies vegetais quanto à tolerância à salinidade, baseando-se na redução do crescimento ou produtividade.

\begin{tabular}{cc}
\hline Redução da Produção (\%) & Classificação \\
\hline $0-20$ & Tolerante (T) \\
$20-40$ & Moderadamente Tolerante (MT) \\
$40-60$ & Moderadamente Sensível (MS) \\
$>60$ & Sensível (S) \\
\hline
\end{tabular}

Fonte: Fageria et al., (2010).

Ao final do experimento foi realizada a qualidade das mudas de noni, utilizando-se os dados de altura de planta $(\mathrm{H})$, diâmetro do colo (DC), área foliar (AF), matéria seca da raiz (MSR), matéria seca da parte aérea (MSPA) e a matéria seca total (MST). Com estes dados de crescimento foi calculado o Índice de Qualidade de Dickson IQD = MST/[(H/DC) + (MSPA/MSR)]), segundo Dickson, Leaf e Hosner (1960) e as relações MSPA/MSR, H/MSPA e H/DC, conforme Carneiro (1995).

Para avaliação do acúmulo de sais no solo, coletaram-se amostras de solos aos 110 dias após aplicação dos tratamentos. As amostras foram acondicionadas em bandejas de alumínio, identificadas e secas em estufa com circulação de ar forçado a $70{ }^{\circ} \mathrm{C}$. Depois de secas e destorroados foram determinados os valores da condutividade elétrica do extrato de saturação (CEes), no laboratório de análise de solo e água para irrigação do IFCE, Campus Sobral.

Para a preparação do extrato de saturação foi pesado $100 \mathrm{~g}$ de solo colocado em Becker de plástico de $400 \mathrm{~mL}$ e adicionado, aos poucos, $25 \mathrm{~mL}$ água destilada. As amostras foram amassadas com espátula de aço inoxidável e deixadas em repouso durante 4 horas. Decorrido esse tempo as pastas saturadas foram transferidas para um funil de Buckner contendo papel de filtro e adaptado a um Kitasato de 500 mL. Foi aplicado a sucção com uma bomba de vácuo e posteriormente coletado o filtrado em Becker de $10 \mathrm{~mL}$. Com o extrato de saturação obtido foi realizada leitura direta em um condutivímetro de bancada.

A análise estatística dos dados foi realizada utilizando-se o programa “ASSISTAT 7.5 BETA”, consistindo da análise de variância, análise de regressão para os efeitos da salinidade e comparação de médias pelo teste de Tukey para os efeitos do ambiente e da matéria orgânica.

\section{RESULTADOS E DISCUSSÃO}

O aumento da concentração de sais na água de irrigação provocou acúmulo de sais no solo, porém, esse efeito foi independente do ambiente de cultivo. Por outro lado, constatouse que tanto na ausência como na presença de matéria orgânica houve um incremento linear crescente da salinidade do solo, sendo os valores sempre maiores na presença do insumo orgânico (CEa) (Figura 1). A superioridade da CEes encontrada nos solos tratados com matéria orgânica pode ser resultado da solubilização dos elementos presentes nesse insumo (Tabela 1), os quais são componentes da salinidade do solo das águas (MELO et al., 2008).

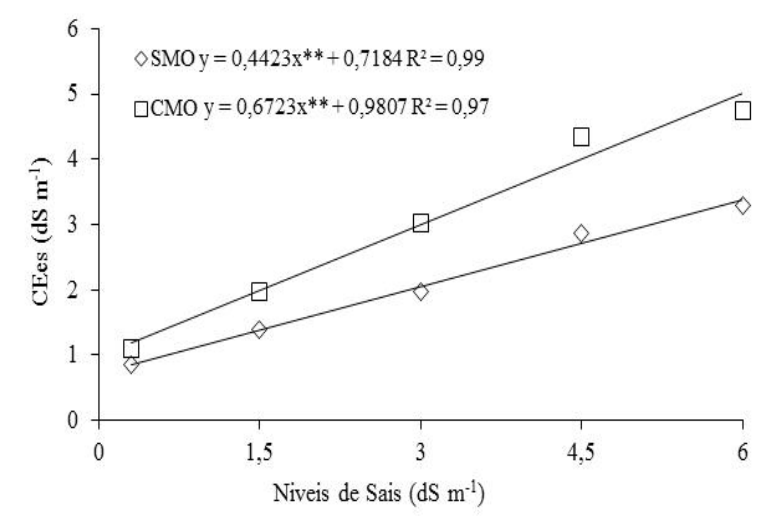

Figura 1. CEes em solos cultivados com plantas de Morinda citrifolia em função da ausência e presença de matéria orgânica, irrigados com água de diferentes níveis de salinidade na profundidade de 0-30 cm aos 110 DAT, Sobral - CE, 2011. 
Pesquisa realizada por Souto et al. (2013) evidenciou que a utilização de água salina na irrigação do noni elevou a salinidade do solo, independentemente da utilização do biofertilizante. Esse resultado diverge dos obtidos no presente estudo, porém isso pode ser explicado pelos quantitativos de fertilizantes orgânicos utilizados nos dois ensaios. Silva et al. (2011) também trabalhando com biofertilizante também encontrou efeito salino desse insumo. Resultados obtidos por (LIMA et al., 2001) também demonstraram que o uso de insumo orgânico de origem bovina incrementa a salinidade do solo. Esses resultados indicam que apesar da expressividade da matéria orgânica na melhoria física, na biologia e na fertilidade a utilização de matéria orgânica também pode incrementar a salinidade dos solos.
A matéria orgânica isoladamente ou a interação dela com a salinidade não exerceu influência sobre a tolerância das mudas de noni à salinidade. Porém, quando se comparam os ambientes, verificaram-se respostas bastante distintas. Sob telado o noni se mostrou tolerante para todos os níveis de salinidade (Tabela 3) e diferentemente das mudas sob céu aberto, não mostraram sintomas visuais de toxidez ou de perda na turgescência ao longo do experimento. Por outro lado, as plantas cultivadas em céu aberto se mostraram tolerantes ou moderadamente tolerantes nos níveis de salinidade de 1,5 e 3,0 dS $\mathrm{m}^{-1}$, respectivamente, sendo consideradas moderadamente sensíveis e sensíveis nos maiores níveis de salinidade.

Tabela 3. Redução percentual da massa seca das raízes (MSR), massa seca da parte aérea (MSPA) e massa seca total (MST) em plantas de noni irrigadas com água salina e sob duas condições de cultivo, aos 110 DAT.

\begin{tabular}{ccrrrrr}
\hline \multirow{2}{*}{ Espécies } & \multirow{2}{*}{ Equações } & $\mathrm{R}^{2}$ & \multicolumn{4}{c}{ Redução em relação ao controle (\%) } \\
\cline { 3 - 7 } & & & $\mathrm{CE}_{1,5}$ & $\mathrm{CE}_{3,0}$ & $\mathrm{CE}_{4,5}$ & $\mathrm{CE}_{6,0}$ \\
\cline { 3 - 7 } & & & \multicolumn{5}{c}{ Céu aberto } \\
MSR & $\mathrm{y}=-1,712 \mathrm{x}+16,6$ & 0,98 & $12,8^{\mathrm{T}}$ & $28,7^{\mathrm{MT}}$ & $44,7^{\mathrm{MS}}$ & $60,6^{\mathrm{S}}$ \\
MSPA & $\mathrm{y}=-3,673 \mathrm{x}+39,9$ & 0,98 & $11,3^{\mathrm{T}}$ & $25,5^{\mathrm{MT}}$ & $39,7^{\mathrm{MT}}$ & $53,8^{\mathrm{MS}}$ \\
MST & $\mathrm{y}=-5,785 \mathrm{x}+57,1$ & 0,98 & $12,5^{\mathrm{T}}$ & $28,2^{\mathrm{MT}}$ & $43.9^{\mathrm{MS}}$ & $59,6^{\mathrm{MS}}$ \\
& & & & & & \\
& & & & & & \\
MSR & $\mathrm{y}=-0,259 \mathrm{x}+6,81$ & 0,62 & $1,7^{\mathrm{T}}$ & $7,6^{\mathrm{T}}$ & $13,6^{\mathrm{T}}$ & $19,5^{\mathrm{T}}$ \\
MSPA & $\mathrm{y}=-0,456 \mathrm{x}+16,37$ & 0,55 & $3,4^{\mathrm{T}}$ & $7,6^{\mathrm{T}}$ & $11,8^{\mathrm{T}}$ & $16,0^{\mathrm{T}}$ \\
MST & $\mathrm{y}=-0,780 \mathrm{x}+23,25$ & 0,62 & $4,0^{\mathrm{T}}$ & $9,1^{\mathrm{T}}$ & $14,1^{\mathrm{T}}$ & $19,1^{\mathrm{T}}$ \\
\hline
\end{tabular}

T, ${ }^{\mathrm{MT}},{ }^{\mathrm{MS}} \mathrm{e}^{\mathrm{S}}$ - Tolerante, moderadamente tolerante, moderadamente sensível e sensível, respectivamente.

O ambiente de cultivo teve forte impacto sobre as variáveis de qualidade de mudas, seja isoladamente ou em associação com a salinidade e a matéria orgânica. Observa-se, de modo geral, que as plantas à céu aberto apresentaram menores relações altura/diâmetro e altura/MSPA e valores substancialmente maiores do IQD, em relação ao ambiente de sombrite
(Tabela 4). A presença de matéria orgânica não influenciou o IQD e a relação H/D, porém reduziu a relação H/MSPA e a relação MSPA/MSR. A salinidade influenciou todas as variáveis de qualidade de mudas, mas interações significativas com outros fatores somente foram observadas para a relação MSPA/MSR e para o IQD. 
Tabela 4. Resumo da análise de variância para o efeito da luminosidade e da irrigação com águas salinas sobre a qualidade das plantas de Morinda citrifolia aos 110 DAT, Sobral - CE, 2011.

\begin{tabular}{cccccc}
\hline \multirow{2}{*}{ FV } & GL & \multicolumn{4}{c}{ Quadrado Médio } \\
\cline { 2 - 5 } & & H/DC & H/MSPA & MSPA/MSR & IQD \\
\hline Bloco & 4 & $0,18^{\text {ns }}$ & $0,20^{\text {ns }}$ & $0,37^{\text {ns }}$ & $5,55^{\text {ns }}$ \\
Amb (a) & 1 & $13,70^{* *}$ & $511,13^{* *}$ & $8,18^{\text {ns }}$ & $288,62^{* *}$ \\
Resíduo (a) & 4 & 0,23 & 0,09 & 1,42 & 2,48 \\
Sal(b) & 4 & $0,43^{* *}$ & $0,32^{*}$ & $3,95^{* *}$ & $44,65^{* *}$ \\
Amb x Sal & 4 & $0,25^{\text {ns }}$ & $0,47^{\text {ns }}$ & $1,42^{*}$ & $32,88^{* *}$ \\
Resíduo (b) & 32 & 0,09 & 0,19 & 0,52 & 1,71 \\
MO (c) & 1 & $0,11^{\text {ns }}$ & $5,02^{* *}$ & $28,47^{* *}$ & $3,29^{\text {ns }}$ \\
Amb x MO & 1 & $1,46^{* *}$ & $2,53^{* *}$ & $2,95^{\text {ns }}$ & $9,62^{* *}$ \\
Sal x MO & 4 & $0,20^{\text {ns }}$ & $0,09^{\text {ns }}$ & $5,59 * *$ & $1,49^{\text {ns }}$ \\
Amb x Sal x MO & 4 & $0,07^{\text {ns }}$ & $0,03^{\text {ns }}$ & $0,39 n \mathrm{~ns}$ & $0,46 \mathrm{~ns}$ \\
Resíduo (c) & 40 & 0,09 & 0,08 & 1,21 & 1,12 \\
\hline CV(a) & - & 13,86 & 16,26 & 41,18 & 31,54 \\
CV(b) & - & 8,83 & 23,70 & 24,95 & 26,20 \\
CV(c) & - & 8,89 & 15,41 & 38,07 & 21,26 \\
Céu Aberto & & $3,15 \mathrm{~b}$ & $1,17 \mathrm{~b}$ & $3,18 \mathrm{a}$ & $6,69 \mathrm{a}$ \\
Telado & $3,89 \mathrm{a}$ & $2,53 \mathrm{a}$ & $2,60 \mathrm{a}$ & $3,30 \mathrm{~b}$ \\
& & & & & \\
Sem matéria orgânica & & $3,51 \mathrm{a}$ & $1,63 \mathrm{~b}$ & $3,42 \mathrm{a}$ & $4,81 \mathrm{a}$ \\
Com matéria orgânica & & $3,49 \mathrm{a}$ & $2,08 \mathrm{a}$ & $2,36 \mathrm{~b}$ & $5,18 \mathrm{a}$ \\
\hline
\end{tabular}

H/DC - relação altura/diâmetro; H/MSPA - altura/massa seca da parte aérea; MSPA/MSR - massa seca da parte aérea/massa seca da raíz e IQD - indice de qualidade de Dickson; **, *significativo a 1 e $5 \%$ de probabilidade respectivamente pelo teste F e ns não significativo. GL - grau de liberdade. CV - coeficiente de variação em porcentagem.

Os maiores valores na relação H/DC observados nas plantas cultivadas em céu aberto mostraram que neste ambiente as plantas apresentaram um maior equilíbrio no seu desenvolvimento apresentando-se, também, mais robusta. O valor de 3,89 $(\mathrm{cm} / \mathrm{mm})$ constatado na relação H/DC na pesquisa com noni em plantas cultivadas sob telado foram menores que os observados por Camara e Endres (2008) em duas espécies arbóreas Mimosa caesalpiniifolia Benth. e Sterculia foetida L., sob diferentes níveis de sombreamento em viveiro e próximos do valor considerado ideal por Marana et al. (2008) para o café, planta da mesma família do noni.

Embora a relação H/MSPA não seja um índice comumente usada para avaliar o padrão de qualidade de mudas, ele pode ser de grande valia, principalmente para predizer o potencial de sobrevivência da muda no campo (GOMES, 2008). O valor de 1,17 (cm/g) observado no noni cultivado em céu aberto inferiu que neste ambiente as plantas apresentaram uma maior capacidade de sobrevivência no campo, pois quanto menor for este índice, mais lignificada será a muda e maior deverá ser a sua capacidade de sobrevivência no campo (GOMES, 2008). Bernardino et al. (2007) trabalhando com mudas de Dalbergia nigra e saturação por bases não observaram efeito significativo para essa variável.

Analisando o efeito isolado dos sais nas relações H/DC e H/MSPA, constatou-se que para cada aumento unitário na CEa a H/DC apresentou redução nos resultados adequandose a um modelo linear (Figura 2A) e na H/MSPA ajustou-se a um modelo polinomial quadrático (Figura 2B). Na relação H/DC 
constatou-se uma redução linear de 0,054 para cada aumento unitário na CEa e já para a relação H/MSPA o menor valor 1,79 $(\mathrm{cm} / \mathrm{g})$ foi constatado quando as

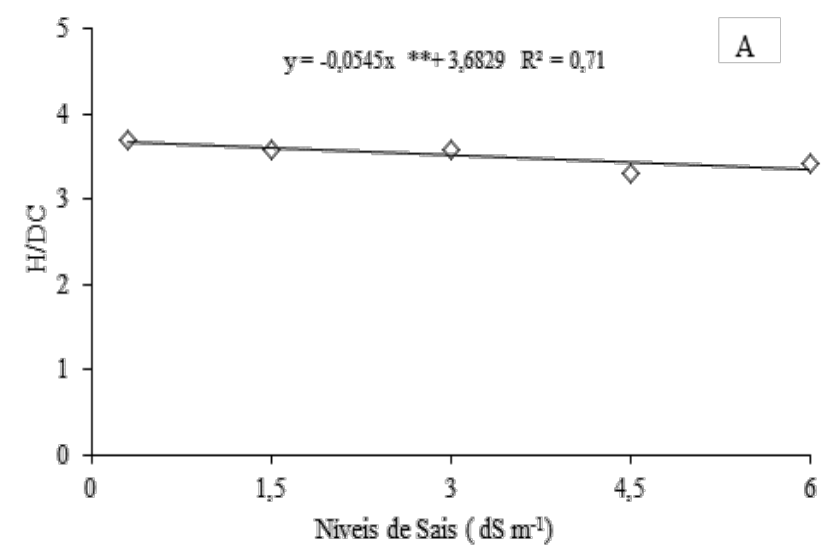

plantas foram irrigadas com água de $4,15 \mathrm{dS} \mathrm{m}{ }^{-1}$ a partir do qual iniciou o acréscimo nos valores da variável.

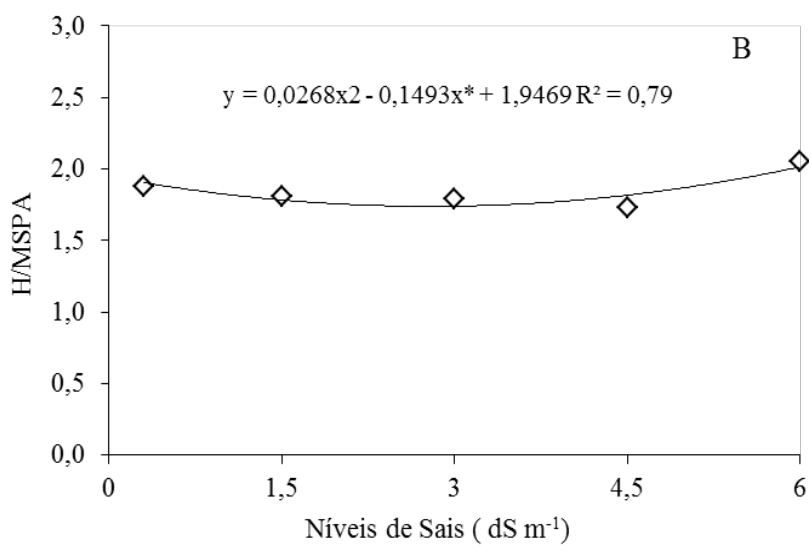

Figura 2. H/DC (A), H/MSPA (B) em plantas de Morinda citrifolia submetidas a níveis crescentes de sais da água de irrigação, Sobral - CE, 2011.

A relação MSPA/MSR aumentou linearmente com o aumento nos teores de sais da água de irrigação nos dois ambientes pesquisados (Figura 3A), porém essa resposta variou com o ambiente de cultivo. Nos tratamentos conduzidos a céu aberto o aumento foi de 0,3116 (g/g) para cada aumento unitário na CEa, sendo esse acréscimo cerca de três vezes maior que no ambiente telado

A relação calculada entre MSPA/MSR é um índice eficiente e seguro para expressar o padrão de qualidade de mudas e pode ser de grande importância quando o plantio ocorre em estações difíceis, onde o fator mais influente na sobrevivência do primeiro ano é um estação quente e seca por muito tempo. Para Silva et al. (2012), além de outros fatores a procedência e o ambiente de cultivo interferem de modo significativo na qualidade das mudas. Os valores de 3,86 (g/g) e 2,89 (g/g), na relação MSPA/MSR, observados nas plantas cultivadas em céu aberto e telado, respectivamente, irrigados com $\mathrm{CEa}=6,0 \mathrm{dS}$ $\mathrm{m}^{-1}$, mostraram que as plantas cultivadas em céu aberto apresentaram valores próximos a 4 valor sugerido por Marana et al. (2008) como ideal para a cultura do café.

Os valores de IQD decresceram linearmente com o aumento da salinidade nos dois ambientes, sendo que esse índice foi sempre maior no ambiente a céu aberto do que no telado, exceto no maior nível de salinidade (Figura 3B). Em outras palavras, as diferenças no IQD entre os dois ambiente decresce com o aumento da salinidade, sendo as diferenças marcantes nas plantas irrigadas com água de baixa salinidade. Os índices de qualidade de Dickson, nas plantas cultivas a céu aberto, variaram entre 9,97 e 3,19, quando irrigados $\mathrm{CEa}=0,3$ e $6,0 \mathrm{~d} \mathrm{Sm}^{-1}$, respectivamente. Já nas cultivadas em telado os índices variaram de 3,59 a 2,97, quando irrigadas com a menor e maior CEa, respectivamente. 

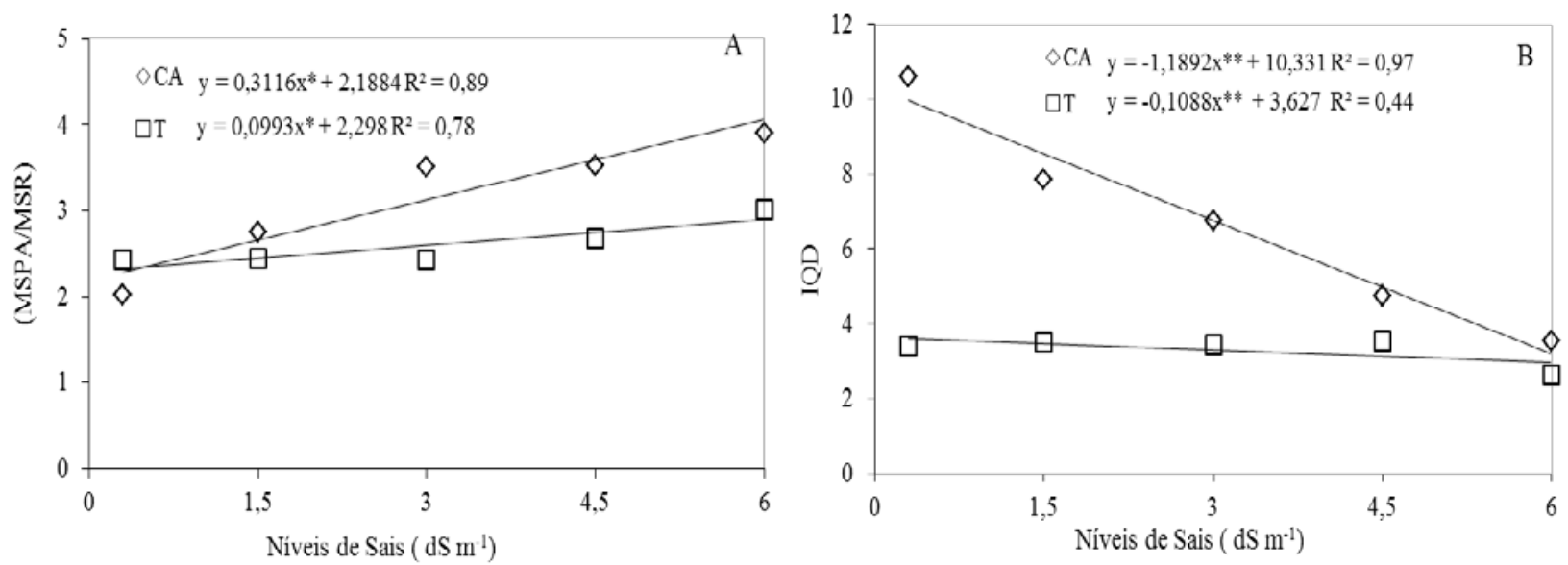

Figura 3. MSPA/MSR (A), IQD (B) de plantas de Morinda citrifolia cultivadas em céu aberto (CA) e telado (T) submetidas a níveis crescentes de sais da água de irrigação aos 110 DAT, Sobral - CE, 2011.

Para Azevedo et al., (2010) o índice de qualidade de Dickson é um bom indicador da qualidade das mudas, pois é considerado o vigor e o equilíbrio da distribuição da biomassa na muda ponderando os resultados de muitas variáveis. Os valores dos IQD observados nas plantas cultivadas a céu aberto embora decrescentes com o aumento dos níveis de sais, foram muito superiores aos observados por Santo et al. (2011) em mudas de Schizolobium amazonicum. Já as cultivadas em telado tomando-se como referência a pesquisa de Santo et al. (2011) apresentaram valores semelhantes de IQD.

Avaliando o efeito da interação sal $\mathrm{x}$ matéria orgânica constatou-se que tanto na ausência como na presença de matéria orgânica houve um incremento linear crescente da salinidade do solo com o aumento da condutividade elétrica da água de irrigação, sendo os valores sempre maiores na presença do insumo orgânico (CEa). Observou-se ainda, que para cada aumento unitário na salinidade da água de irrigação houveram incrementos lineares crescentes na condutividade elétrica do extrato de saturação (CEes) de $0,67 \mathrm{dS} \mathrm{m}^{-1}$ nos tratamentos acrescidos de matéria orgânica e de $0,44 \mathrm{dS} \mathrm{m}^{-1}$ nos tratamentos sem o insumo orgânico. O maior valor da CEes foi de 5,0 dS $\mathrm{m}^{-1}$ observado na presença de matéria orgânica quando as plantas foram irrigadas com água de maior condutividade elétrica (Figura 4).

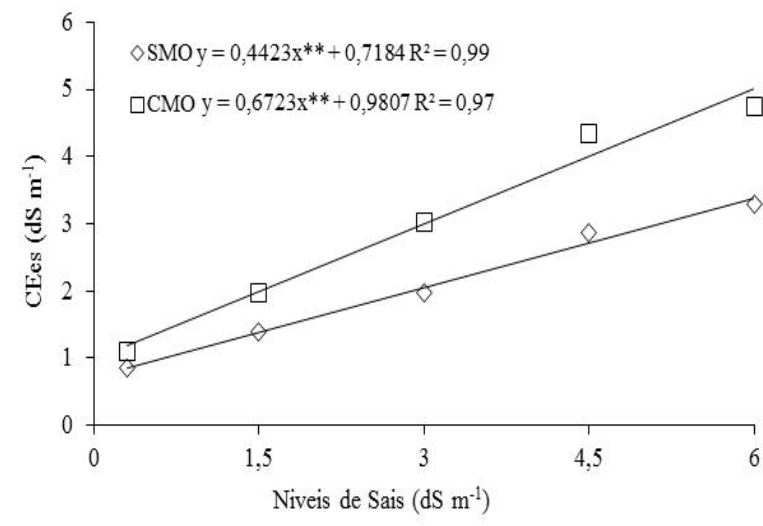

Figura 4. CEes em solos cultivados com plantas de Morinda citrifolia em função da ausência e presença de matéria orgânica, irrigados com água de diferentes níveis de salinidade na profundidade de 0-30 cm aos 110 DAT, Sobral - CE, 2011.

Pesquisa realizada por Souto (2013) evidenciou que a utilização de água salina na irrigação do noni elevou a salinidade do solo, independentemente da utilização do biofertilizante. Esse resultado diverge dos obtidos no presente estudo, pois se verificouse que embora a salinidade tenha aumentado tanto na presença como na ausência da matéria orgânica, os valores e os incrementos foram significativamente maiores na presença do insumo orgânico, demonstrando a existência de interação entre esses fatores.

\section{CONCLUSÕES}

As plantas de noni cultivadas sob condições de telado se mostraram mais 
tolerantes à salinidade do que as cultivadas à céu aberto.

O ambiente à céu aberto proporcionou melhor qualidade de mudas de Morinda citrifolia.

A matéria orgânica não atenuou os efeitos da salinidade sobre o crescimento inicial e da qualidade de mudas de noni nos ambientes avaliados.

\section{REFERÊNCIAS BIBLIOGRÁFICAS}

AZEVEDO, I. M. G.; ALENCAR, R. M.; BARBOSA, A. P.; ALMEIDA, N. O. Estudo do crescimento e qualidade de mudas de marupá (Simarouba amara Aubl) em viveiro. Acta Amazonica, v.40, n.1, p.157-164, 2010.

BASAR, S.; UHLENHUT, K.; HÖGGER, P.; SCHÖNE, F.; WESTENDORF, J. Analgesic and antiinflammatory activity of Morinda citrifolia L. (Noni) fruit. Phytotherapy Research, v.24, n.1, p.38-42, 2010.

BERNARDINO, D. C. D. S.; PAIVA, H. N. D.; NEVES, J. C. D. L.; GOMES, J. M.; MARQUES, V. B. Influência da saturação por bases e da relação Ca:Mg do substrato sobre o crescimento inicial de jacarandá-da-bahia (Dalbergia nigra(Vell.) Fr. All. Ex Benth.). Revista Árvore, v.31, n.4, p.567-573, 2007.

CÂMARA, A. C.; ENDRES, L. Desenvolvimento de mudas de duas espécies arbóreas: Mimosa caesalpiniifolia Benth. e Sterculia foetida L. sob diferentes níveis de sombreamento em viveiro. Floresta, v.38, n.1, p.43-51, 2008.

CAVALCANTE, L. F.; RODOLFO JÚNIOR, F.; SÁ, J. R.; CURVELO, C. D. S.; MESQUITA, E. F. Influência da água salina e matéria orgânica no desempenho do maracujazeiro-amarelo e na salinidade do substrato. Irriga, v.12, n.4, p.505-518, 2007.

DANDENGO, M. C. J.; SOUSA, E. F.; REIS, E. F.; AMARAL G. G. Crescimento e qualidade de mudas de café conilon produzidas em diferentes recipientes e níveis de sombreamento. Coffee Science, v.8, n.4, p.500-509, 2014.

DANTAS, J. A.; NETO, E. B.; BARRETO, L. P.; SANTOS, M. V. F. Efeito da salinidade sobre o crescimento e composição mineral de seis clones de Pennisetum. Revista Ciência Agronômica, v.37, n.1, p.97-101, 2006.

FAGERIA, N. K.; SOARES FILHO, W. S.; GHEYI, H. R. Manejo da Salinidade na agricultura: estudos básicos e aplicados. In: GHEYI, H. R.; DIAS, N. S.; LACERDA, C. F. Melhoramento genético vegetal e seleção de cultivares tolerantes à salinidade. Fortaleza: INCTSal, cap.13, p.205-216, 2010. 18 Fev. 2017.

FERNANDES, C. A. D.; FILGUEIRA, M. A.; MARINHO, E. Estudos preliminares do "deserto salino" e sua influência na poluição do ar na cidade de Mossoró/RN. Revista Verde de Agroecologia e Desenvolvimento Sustentável, v.1, n.3, p.152-163, 2008.

FREIRE, J. L. O; CAVALCANTE, L. F.; REBEQUI, A. M.; DIAS, T. J.; LUNA SOUTO, A. G. Necessidade hídrica do maracujazeiro amarelo cultivado sob estresse salino, biofertilização e cobertura do solo. Revista Caatinga, v.24, n.1, p.82-91, 2011.

GOMES, K. C. O.; PAIVA, H. N.; NEVES, J. C. L.; BARROS, N. F.; SILVA, S. R. Crescimento de mudas de garapa em reposta à calagem e ao fósforo. Revista Árvore, v.32, n.3, p.387-394, 2008.

LIMA, K. L.; CAVALCANTE, L. F.; FEITOSA FILHO, J. C. Efeito de fontes e níveis de salinidade da água de irrigação sobre a germinação e o crescimento da pinheira. Engenharia Agrícola, v.21, p.135-144, 2001.

MARANA, J. P., MIGLIORANZA, É., FONSECA, É. D. P., KAINUMA, R. H. Seedling quality in coffee grown in 
containers. Ciência Rural, v.38, n.1, p.39-45, 2008.

MELO, M. R.; BARROS, C. F. M.; SANTOS, M. P.; ROLIM, M. M. Correção de solos salinosódicos pela aplicação de gesso mineral. Revista Brasileira de Engenharia Agrícola e Ambiental, v.12, n.4, p.376-380, 2008.

PEDROTTI, A.; CHAGAS, R. M.; RAMOS, V. C.; NASCIMENTO PRATA, A. P.; LUCAS, A. A. T.; SANTOS, P. B. Causas e consequências do processo de salinização dos solos. Electronic Journal of Management, Education and Environmental Technology, v.19, n.2, p.1308-1324, 2015.

QUEIROZ, S. O. P.; TESTEZLAF, R.; MATSURA, E. E. Metodologia para avaliação da salinidade do solo em ambiente protegido. Irriga, v.14, n.3, p.383-397, 2009.

RAJENDRAN, K.; DEVARA, J, P. Biomass and nutrient distribution and their return of Casuarina equisetifolia inoculated with biofertilizers in farm land. Biomass and Bioenergy, v.26, n.3, p.235-249, 2004.

SANTOS, R. L.; VIEIRA, T. A.; SANTOS, D. S.; SILVA, L. C. B. Emergência, crescimento e padrão de qualidade de mudas de Schizolobium amazonicum Huber ex Ducke sob diferentes níveis de sombreamento e profundidades de semeadura. Revista de Ciências Agrárias, v.52, n.1, p.87-98, 2011.

SILVA, F. A S.; AZEVEDO, C. A. V. Versão do programa computacional Assistat para o sistema operacional Windows. Revista Brasileira de Produtos Agroindustriais, v.4. n.1, p.71-78, 2009.

SILVA, F. C. Manual de Análises Químicas de Solos, Plantas e Fertilizantes. Embrapa Informação Tecnológica, Rio de Janeiro: Embrapa Solos, 2009. 627p.

SILVA, R. F.; SAIDELLES, F. L.; KEMERICH, P. D.; STEFFEN, R. B.; SWAROWSKY, A.; SILVA, A. S. Crescimento e qualidade de mudas de Timbó e Dedaleiro cultivadas em solo contaminado por cobre. Revista Brasileira de Engenharia Agrícola e Ambiental, v.16, n.8, p.881-886, 2012.

SINGH, D. R. Morinda citrifolia L. (noni): a review of the scientific validation for its nutritional and therapeutic properties. Journal of Diabetes and Endocrinology, v.3, n.6, p.77-91, 2012.

SOUTO, A. G. L.; CAVALCANTE, L. F.; NASCIMENTO, J. A. M. D.; MESQUITA, F. D. O.; LIMA NETO, A. J. D. Comportamento do noni à salinidade da água de irrigação em solo com biofertilizante bovino. Irriga, v.18, n.3, p.442-453, 2013.

YANG, J.; GADI, R.; PAULINO, R.; THOMSON, T. Total phenolics, ascorbic acid, and antioxidant capacity of noni (Morinda citrifolia L.) juice and powder as affected by illumination during storage. Food Chemistry, v.122, n.3, p.627-632, 2010. 